\title{
DESCOPERIRI MONETARE ANTICE ŞI BIZANTINE, MAI VECHI ŞI MAI NOI, DIN ROMÂNIA ŞI SERBIA (VII) $)^{1}$
}

DELIA MOISIL

\section{REZUMAT:}

Această cronică numismatică prezintă tipuri de descoperiri variate: tezaure, descoperiri izolate și de sit, sau incerte. Sunt menționate: un tezaur mixt, format din monede romane de aur și din argint, descoperit în 1858, la Banatska Palanka (Uj Palanka), Serbia, pe linia Dunării - care poate fi datat acum mai sigur, utilizând cataloage numismatice de referință mai noi; un grup de 29 de denari dintr-un tezaur roman mai vechi, de la Sângeorgiu de Câmpie, jud. Mureș, având un loc de descoperire mai clar precizat; un grup de 72 de denari romani având cea mai recentă monedă de la Marcus Aurelius, descoperiți împreună undeva în zona Hațegului, în jud. Hunedoara; un grup de antoninieni (de la Elagabal la Gallienus) ce au fãcut parte dintr-un tezaur provenind din sudul României (București?); un mic depozit de drahme şi hemidrahme de la Callatis, descoperit în zona Dobrogei; un grup de monede romane de bronz (Provincia Dacia și Viminacium) de la mijlocul sec. al III-lea, provenind de la Turda, jud. Cluj; două tetradrahme thasiene, probabil parte a unui tezaur mai mare, din zona Sălajului.

Se adaugă trei descoperiri monetare izolate: semis de bronz, de la Traian, descoperit în fosta provincie romană Dacia, în Transilvania, într-un loc neprecizat; o monedă de bronz de la Traian descoperită la Bădeni, com. Moldovenești, jud. Cluj; și un denarius de la Vespasianus, găsit în afara complexului arheologic, la Podul Tărtaria Vest, în timpul săpăturilor arheologice din 2016.

De asemenea, 12 monede variate (de la antice la bizantine) fără loc de descoperire sigur, de pe teritoriul Românei; pentru cinci dintre ele, piese romane târzii, emise în monetării balcanice și orientale, sunt prezentate și rezultatele analizelor XRF de compoziție a metalului.

\section{Abstract: Ancient and Byzantine Coin Finds from Romania and Serbia (VII)}

This numismatic chronicle is focusing on several types of finds: hoards, single and stray finds, or uncertain. The hoards that are mentioned are: in Banatska Palanka (Uj Palanka), Serbia, on the Danube line, a hoard found in 1858 mixing gold and silver roman coins, that is possible to be dated or identified more accurate now ussing recent numismatics reference catalogues; a group of 29 denarii from an old roman hoard, Sângeorgiu de Câmpie, Mureș dept., with a more precise place of finding: the point called La Comoară; a group of 72 roman denarii with the later coin from Marcus Aurelius found together in the area of Hațeg, Hunedoara department; a group of antoniniani (from Elagabal to Gallienus) part of a hoard from Southern Romania (Bucharest?); a small deposit of coins from Callatis (drachm and hemidrachm), found in Dobroudgea; a group of bronze coins (Provincia Dacia and Viminacium types) from the middle of the 3rd century AD, from Turda, Cluj department; two thasian tetradrachmes, part of a possible larger hoard, from Sălaj area.

Three single finds are added in this chronicle: a bronze semis from Traianus found in the former roman province Dacia, in Transylvania; a bronze coin from Traianus found in Bădeni, Moldovenești, dept. of Cluj; and a denarius of Vespasianus, found outside the archaeological complex in Tartaria, the western bridge, during the excavations of 2016.

\footnotetext{
1 Articolul de față continuă seria cronicilor numismatice începută în anul 2009, având ca scop publicarea după criterii științifice sau semnalarea prezenței materialului numismatic antic (în principal) și bizantin, provenind din orice sursă disponibilă, din zona României, și la care am avut acces direct. Seria amintită va fi publicată, începând din acest an, în revista Cercetări Arheologice, în încercarea de a o aduce mai aproape de unul din domeniile beneficiare majore - cel al arheologiei. Numerele anterioare ale cronicii numismatice (Moisil, D. 2009. Descoperiri monetare antice din România şi din zona Balcanilor. Cercetări numismatice 15: 79-86; Moisil, D. 2010. Descoperiri monetare antice din România, Republica Moldova şi din zona Balcanilor (2). Cercetări numismatice 16: 415-430; Moisil, D. 2011. Descoperiri monetare antice din România (3). Cercetări numismatice 17: 209 -223; Moisil, D. 2012. Descoperiri monetare antice și bizantine din România (4). Cercetări numismatice 18: 293 - 322; Moisil, D. 2013-2014. Descoperiri monetare antice din România (5-6). Cercetări numismatice 19-20: 167-229) pot fi accesate pe https:// www.mnir.ro/index.php/cercetări-numismatice.
} 
Twelve ancient to Byzantine coins (Justinianus I) are listed with no certain place of finding at all, in Romania. The XRF analyses of the surface of five coins from eastern and balcanic mints in the late roman period was added.

CUVINTE CHEIE: monedă, tezaur, Roman, Bizantin, antic, limes, aur, argint, bronz, drahmă, hemidrahmă, denar, as, dupondius, centenionalis, AE3, Apollonia, Callatis, Roma, Thasos, analize XRF, Alba, Banatska Palanka, Banat, Bădeni, București, Constanța, Cluj, Dunăre, Dobrogea, Hațeg, Hunedoara, Moldovenești, Mureș, Oltenia, Romania, Serbia, Sălaj, Sângeorgiu de Câmpie, Sânpetru de Câmpie, Tărtăria, Turda, Transilvania.

KEYWORDS: coin, hoard, Roman, Byzantine, ancient, limes, gold, silver, bronze, drachm, hemidrachm, tetradrachm, denarius, asses, dupondius, centenionalis, AE3, Apollonia, Callatis, Rome, Thasos, XRF analyses, Alba, Banatska Palanka, Banat, Bădeni, București, Constanța, Cluj, Danube, Dobrogea, Hațeg, Hunedoara, Moldovenești, Mureș, Oltenia, Romania, Serbia, Sălaj, Sângeorgiu de Câmpie, Sânpetru de Câmpie, Tărtăria, Turda, Transylvania.

\section{Banatska Palanka (Uj Palanka), Serbia , tezaur, 1858}

Reluăm aici câteva informaţii despre un tezaur găsit în secolul al XIX-lea, care a rămas ca ansamblu în afara circuitului științific autohton principal (probabil datorită caracterului lui compozit, ce sugerează reutilizarea pieselor mai vechi sau preluarea unor informații eronate de către Böhm 1861). Din datele păstrate (Böhm 1861, 320-321), tezaurul, în a cărui componență intrau șapte monede romane (trei de aur, patru de argint) a fost găsit în luna martie a anului 1858, la dislocarea din rădăcini a unui dud în Uj Palanka (Nova Palanka); piesele se eșalonau de la Augustus la Honorius, toate fiind foarte bine conservate. Ele au intrat în colecția constituită de Leonhard Böhm înainte de 1861, anul publicării Istoriei Banatului Timişoarei (Böhm 1861, 320).

Autorul a furnizat împăratul emitent și descrierea detaliată a reversului pentru fiecare monedă, ceea ce ne-a permis identificarea mai multor emisiuni după cataloage recente și o datare mai precisă. Am păstrat în catalog, așa cum apare la L. Böhm, descrierea pieselor (cu litere cursive).

\section{Augustus}

denarius

Monetărie spaniolă

RIC $1^{2} 114$, RIC $1^{2} 116$ [cu legenda de revers în exergă și diferențe în legenda de avers]; RIC $1^{2}$ 118, RIC $1^{2} 120$ [cu legenda în câmp (SP-QR) și diferențe în legenda de avers]; monetărie spaniolă, a. 18 î. Hr.

S.P.Q.R. Arc triumfal sub care se află un car cu trofee. AR (Böhm 1861, 320, 1)

\section{Tiberius}

aureus

Roma

RIC $1^{2} 25$, RIC $1^{2} 27$ sau RIC $1^{2} 29$, a. 36-37 d. Hr.

PONTIF. MAXIM. Divinitate așezată pe tron, cu lance în mâna dreaptă și ramură în mâna stângă. $A V$. (Böhm 1861, 320, 2)

\section{Domitianus \\ denarius}

Roma

RIC $2^{2}$ 736, Roma, a. 92, 1 ianuarie - 13 septembrie sau RIC $2^{2}$ 762, Roma, a. 93, 14 septembrie - 94, 13 septembrie.

RIC 2 176, Roma, a. 93-94 d. Hr. sau RIC 2 179, Roma, a. 94 d. Hr.

IMP. XXII. COS. XVI. CENS. P. P. Minerva în picioare, cu o bufniță la picioare. AR. (Böhm 1861, $320,3)$ 
4. Traianus

denarius

MIR 276 (Dacia spre dr.), Roma, a. 107 (a doua jumătate)-108 d. Hr.; RIC 2, 96 a-b; Strack 157 sau MIR 283 (Dacia spre st.), Roma, a. 108-109 d. Hr.; RIC 2, 98 a, b, Strack 156.

COS. V.P.P.S.P. Q. R. OPTIMO. PRINC. Dacia așezată pe un morman de arme. Dedesubt, DAC. CAP. AR. (Böhm 1861, 321, 5)

\section{Antoninus Pius}

denarius

Roma

RIC 3, 250-252, Roma, a. 155-156 d. Hr.

TR. POT.XIX.COS. IIII Personaj feminin, în picioare, ținînd cornucopiae. AR. (Böhm 1861, 320, 4)

6. Iulianus II

solidus

Antiochia

RIC 8, 195-200, officina Z, a. 361-363.

VIRTVS.EXERCITVS. ROMANORVM. İmpăratul în picioare, cu un steag într-o mână, târând de păr cu cealaltă un sclav; în exergă, AHTZ. AV. (Böhm 1861, 321,6)

\section{Honorius}

solidus

RIC 10, 1287, Ravenna (în stilul atelierelor de la Milano și Aquilea), a. 402-403, 405-406. Sau RIC 10, 1319, 1321, 1323, 1326 or 1328, Ravenna, după moartea lui Arcadius (1 mai 408 - 15 august 423).

VICTORIA. AVGGG. Impăratul cu un picior așezat peste un prizonier culcat (la pământ); în câmp, R. V.; în exergă, COMOB. AV. (Böhm 1861, 321, 7)

\section{Bădeni, com. Moldovenești, jud. Cluj}

Piesa provine de pe teritoriul satului Bădeni (Al. Süto), de la un locuitor al acestuia; fără detalii suplimentare. RAN menționează la Bădeni o aşezare romană datată în sec. II-III (cod RAN 58749.01).

1. Imperiul Roman
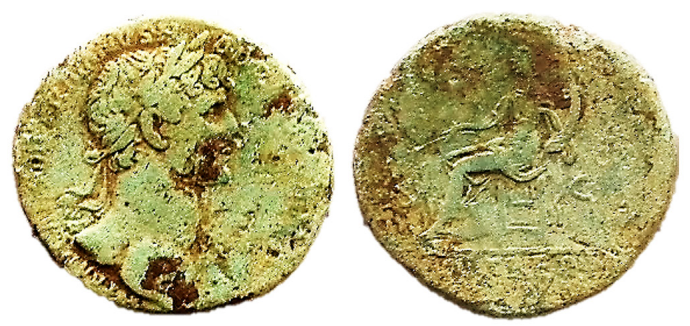

Traianus

sestertius

Avers: IMP CAES [NER? sau AR?] TRAIAN[V]S [...]. Bustul lui Traian văzut 34 din față, spre dr.; laureat; aegis pe umărul st., şi balteus.

Revers: Legenda circulară [SENATVS POPVLVS QVE ROMANVS]; FORT RED în exergă, S-C în câmp. Divinitate (Fortuna) așezată pe tron, ținând cârmă în dr. și cornucopiae pe brațul st.

MIR 542, Roma, a. 114, iarna - 116, la început: rv. MIR 542, var. 2, dar bustul MIR 542tt+-1 (pl. 109, 542tt+-1; pl. 154, 534tt+ și 542tt+-1), cu globul bătut în afara flanului monetar, sau nelizibil.

AE, ax: 6, greutate: 24.71 g. MNIR custodie, nr. prov. 65 . 


\section{București (?), tezaur, sfârșitul anilor ' $70(?)$}

Grup de antoninieni achiziționat la finalul anilor ' 70 , din București (Al. Süto); probabil parte a unui tezaur monetar, împrăștiat în mediul colecționarilor de monede. MNIR custodie.

1. Imperiul Roman

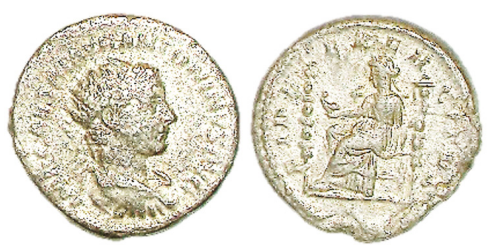

Elagabalus

antoninianus

Avers: IMP CAES M AVR ANTONINVS AVG, bust 3/4 văzut din semiprofil, radiat, drapat, spre dr.

Revers: FIDES EXERCITVS, Fides așezată pe tron spre st., ținând în mâna dr. o acvilă; de o parte și de alta a tronului, câte un stindard.

RIC 70, Roma, a. 218-222.

AR, ax: 11, greutate: 3.98 g. MNIR custodie, nr. prov. 36 .

2. Imperiul Roman

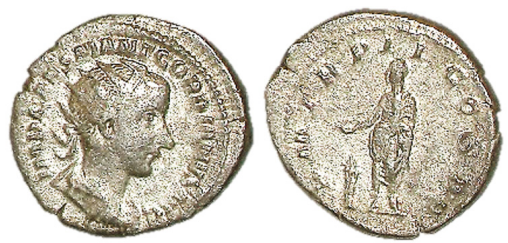

Gordianus III

antoninianus

Avers: IMP CAES M ANT GORDIANVS AVG, bust drapat, cu coroană radiată, spre dr.

Revers: P M TR P II COS PP, Gordian în picioare, văzut din faţă, cu capul spre st., în togă, cu văl, aducând sacrificii deasupra unui altar aprins aflat în câmp st., dintr-o patera ținută în mâna dr.

RIC 4, 3, 37; pl. 1, 13; Roma, a. 240 (1 ianuarie - martie(?) ).

AR, ax: 12, greutate: 3.13 g. MNIR custodie, nr. prov. 32 .

3. Imperiul Roman

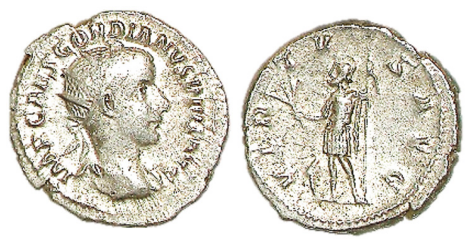

Gordianus III

antoninianus

Avers: IMP CAES GORDIANVS PIVS AVG, bust drapat, cu coroană radiată, spre dr.

Revers: VIRTVS AVG, Virtus în picioare, cu capul spre st., ținând ramură și lance; scut la picioare, în câmp st. jos. RIC 4, 3, 56, Roma, a. 240, martie-mai(?).

AR, ax: 11, greutate: 3.90 g. MNIR custodie, nr. prov. 46. 
4. Imperiul Roman

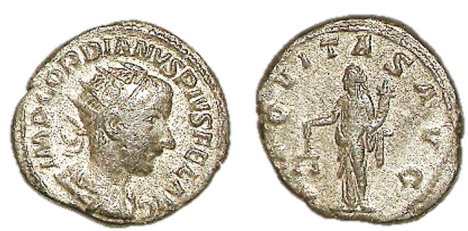

Gordianus III

antoninianus

Avers: IMP GORDIANVS PIVS FEL AVG, bust drapat, cu o coroană radiată, spre dr.

Revers: AEQVITAS AVG, Aequitas, în picioare, privind spre st., ţinând în mâna dr. o balanţă şi în mâna st. cornucopiae.

RIC 4, 3, 63; pl. 1, 19; Roma, a. 240.

AR, ax: 10, greutate: 3.49 g. MNIR custodie, nr. prov. 33 .

\section{Imperiul Roman}

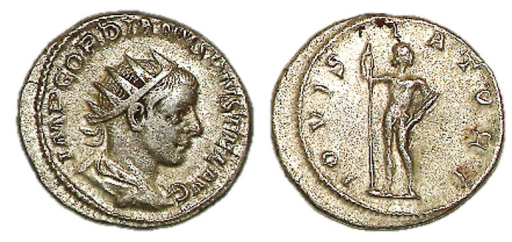

Gordianus III

antoninianus

Avers: IMP GORDIANVS PIVS FEL AVG, bust drapat, cu o coroană radiată, spre dr.

Revers: IOVI S-TATORI, Jupiter nud, în picioare, văzut din faţă, privind spre dr., ținând sceptru lung și fulger.

RIC 4, 3, 84, Roma, a. 241-3.

AR, ax: 8 , greutate: 4.29 g. MNIR custodie, nr. prov. 31 .

6. Imperiul Roman

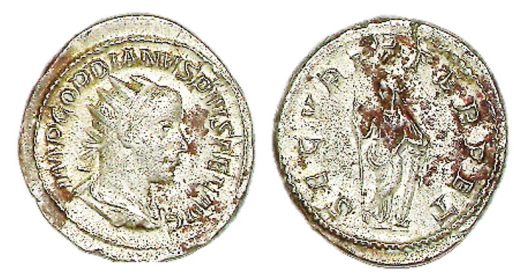

Gordianus III

antoninianus

Avers: IMP GORDIANVS PIVS FEL AVG, bust cu barbă, radiat, drapat, spre dr.

Revers: SECVRIT PERPET, Securitas în picioare, cu capul spre st., sprijinită cu mâna st. pe o coloană scurtă și ținând un sceptru în mâna dr.

RIC 4, 3, 152, Roma, a. 244, ianuarie.

AR, ax: 8, greutate: 4.64 g. MNIR custodie, nr. prov. 45 . 
7. Imperiul Roman

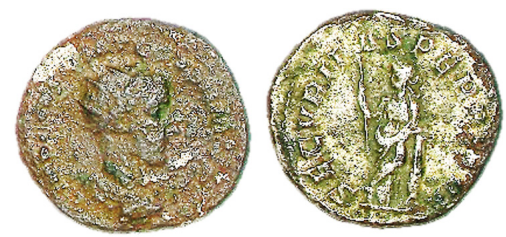

Gordianus III(?)

antoninianus

Avers: IMP [...], bust drapat, cu coroană radiată, spre dr.

Revers: SECVRITAS PERPETVA, Securitas, în picioare, cu capul spre st., cu picioarele încrucişate, ținând în dr. un sceptru și sprijinindu-și cotul st. pe o coloană scurtă.

RIC 4, 3, 153(?); pl. 3, 6(?); Roma, a. 244, ianuarie.

AR, ax: 5, greutate: $3.51 \mathrm{~g}$. MNIR custodie, nr. prov. 37 .

8. Imperiul Roman

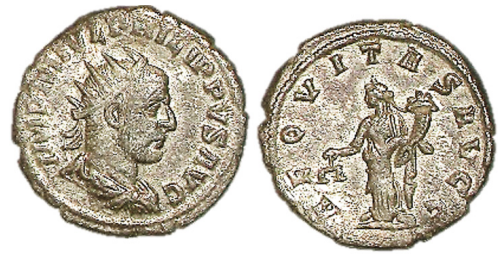

Filip Arabul

antoninianus

Avers: IMP M IVL PHILIPPVS AVG, bust cu barbă, drapat, cu o coroană radiată, spre dr.

Revers: AEQVITAS AVGG, Aequitas, în picioare, privind spre st., ţinând în mâna dr. o balanţă şi în mâna st. cornuсоріае.

RIC 4, 3, 27 b, Roma, nedatată (244-247).

AR, ax: 8, greutate: $3.20 \mathrm{~g}$. MNIR custodie, nr. prov. 34 .

9. Imperiul Roman

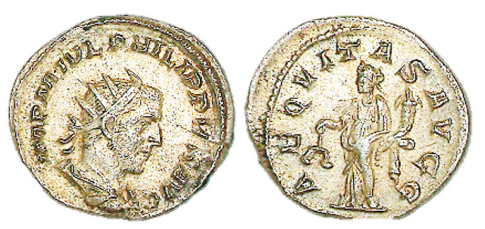

Filip Arabul

antoninianus

Avers: IMP M IVL PHILIPPVS AVG, bust cu barbă, cu o coroană radiată, drapat, spre dr.

Revers: AEQVITAS AVGG, Aequitas în picioare spre st., cu balanţă și cornucopiae în mâini.

RIC 4, 3, 27 b, Roma, nedatată (244-247).

AR, ax: 12, greutate: 3.13 g. MNIR custodie, nr. prov. 44. 
10. Imperiul Roman

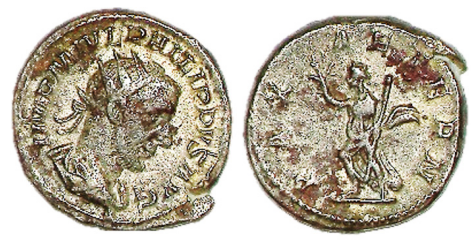

Filip Arabul

antoninianus

Avers: IMP M IVL PHILIPPVS AVG, bust cu barbă, cu o coroană radiată, drapat, cuirasat, spre dr.

Revers: PAX AETERN, Pax pășind spre st. (alergând), ținând o ramură de măslin și sceptru.

RIC 4, 3, 41, Roma, a. 244.

AR, ax: 7/8, greutate: 5.08 g. MNIR custodie, nr. prov. 43.

11. Imperiul Roman

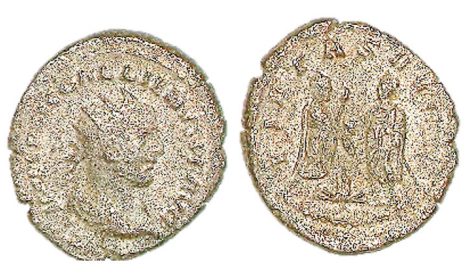

Gallienus

antoninianus

Avers: IMP C P LIC GALLIENVS P F AVG, bust cu barbă, drapat, cu o coroană radiată, spre dr.

Revers: PIETAS AVGG, Valerian și Gallienus față în față, aducând sacrificii deasupra unui altar aflat la mijloc, între ei.

RIC 5, 1, 447, Asia, nedatată (a. 255-259).

AR, ax: 8, greutate: $3.92 \mathrm{~g}$. MNIR custodie, nr. prov. 35 .

\section{Cluj (Napoca?), jud. Cluj, tip de descoperire neprecizat}

Patru monede antice (o drahmă de tip Apollonia și trei monede romane imperiale de bronz) ar proveni din zona Clujului (Al. Süto), fără alte detalii. MNIR custodie.

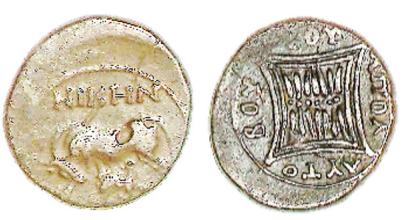

1. Imitație turnată după o drahmă Apollonia (Niken/Autoboulou)

Avers: Legenda NIKHN deasupra unei vaci spre st., cu vițel sugând, spre dr.

Revers: АПO $\Lambda$-AYTO-BOY- VOY, pătrat cu laturile duble, cu decor stelat dublu, mai puțin diferențiat decât în cazul altor emisiuni monetare ale Apolloniei. $\Lambda$ final (din AYTOBOY $\Lambda$ OY), întors cu 180 de grade.

Tip Ceka 88.

AR, ax: 8, greutate: $2.92 \mathrm{~g}$. Cu urme de turnare (gol de aer) pe corpul vacii.

MNIR custodie, nr. prov. 39. 


\section{Domitian}

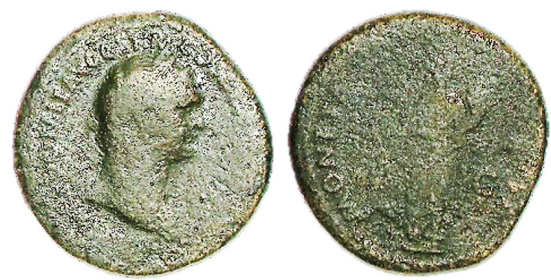

as

Avers: [...]DOMIT AVG GERM COS XI?[CENS...], bust spre dr. al împăratului, drapat, cu cunună de lauri.

Revers: MONETA - [AVGVSTI?], S-C în câmp. Moneta în picioare, cu capul spre st., ținând cornucopiae pe brațul st.; în câmp st., obiect neclar (balanță?).

RIC $2^{2} 384(?)$, a. 85 .

AE, ax: 8, greutate: 11.82 g. MNIR custodie, nr. prov. 72.

3. Imperiul Roman
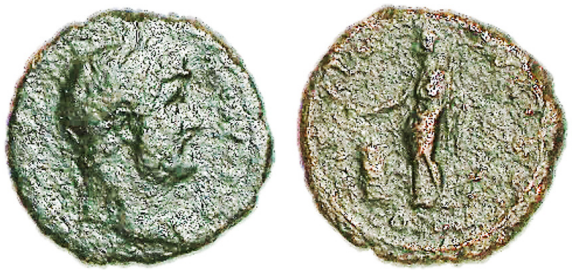

Hadrianus

as

Avers: Bustul lui Hadrian, cu barbă, purtând cunună de lauri, spre dr.

Revers: COS IIII în exergă. Divinitate în picioare ținând un obiect dificil de identificat (sceptru, ramură de palmier) în mâna st. și aducând cu dr. sacrificii dintr-o patera(?) deasupra unui altar aflat în câmp st. jos. Legendă greu lizibilă în exergă (FORT RED?, CON...).

AE, ax: 6, greutate: 12.96 g. MNIR custodie, nr. prov. 73.

\section{Imperiul Roman}
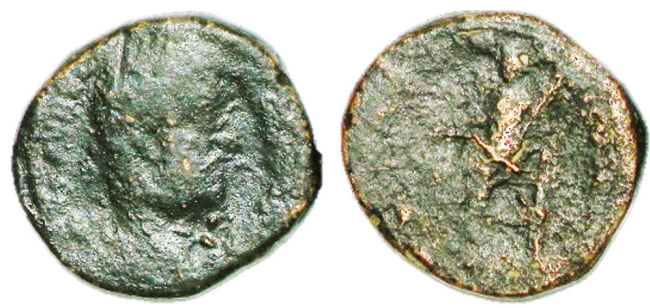

Emitent nedeterminat

sestertius

Avers: Bust drapat, spre dr., cu cunună (de lauri?).

Revers: Divinitate așezată pe tron spre st., ținând în mâna st. sceptru(?).

Sec. I-III.

AE, ax: 8, greutate: 20.9 g. MNIR custodie, nr. prov. 71 . 


\section{Constanța(?), jud. Constanța, posibil tezaur, după 1990}

Două monede de argint callatiene, achiziționate împreună din Constanța (Al. Süto); cu urme de ardere, mai accentuate pe cea de-a doua piesă. MNIR custodie.

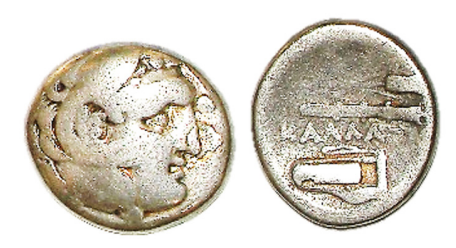

1. Callatis

Drahmă

Avers: Anepigraf. Capul lui Herakles, cu blana leului din Nemea, spre dr.

Revers: Legenda KA $\Lambda \Lambda$ ATI, dispusă median; deasupra, măciucă și spic de grâu spre d.; dedesubt, gorytos (tolbă pentru săgeți și arc de tip scitic; arcul este neclar, ștanța de revers fiind bătută parțial în afara flanului) spre dr.

Pick 199.

Moushmov 202, pl. I, 13; cca 281-200 î. Hr.

SNG Stancomb 63; prima jumătate a sec. al III-lea î. Hr.;

SNG Copenhaga 176 (octobol), sec. al III-lea î. Hr.

AR, ax: 10/11, greutate: 4.67 g. Uzată. MNIR custodie, nr. prov. 38.

\section{Callatis}

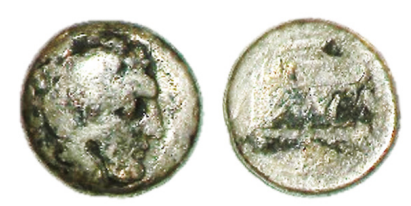

hemidrahmă

Avers: Anepigraf. Capul lui Herakles, cu blana leului din Nemea, spre dr.

Revers: Legenda KA $\Lambda \Lambda$ A, dispusă median; deasupra, gorytos (tolbă cu săgeți și arc de tip scitic) spre st.; dedesubt, măciucă spre dr. și spic de grâu spre st.

Pick 200 (2).

SNG Copenhaga 177 (tetraobol), sec. al III-lea î. Hr..

SNG Stancomb 64 (unde nu este vizibil spicul), prima jumătate a sec. al III-lea î. Hr.

AR, ax: 12, greutate: 2.96 g. Uzată. MNIR custodie, nr. prov. 1.

\section{Dobrogea Passim (Constanța ?), posibil tezaur, după 1990}

Trei monede romane, dintre care două cu patină identică, achiziţionate împreună, după 1990, de la Constanţa (Al. Süto). MNIR custodie.

1. Imperiul Roman

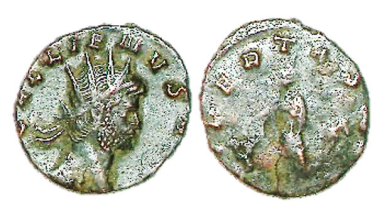

Gallienus (singur)

antoninianus

Avers: [...?] GALLIENVS [AVG], bust cu barbă, spre dr., purtând cunună radiată.

Revers: [L]IBERTAS [AVG...?], Libertas în picioare spre st., cu atribute neclare; XI? în câmp dr.

RIC 233(?), Roma, nedatat (post 259).

AE, ax: 11/12, greutate: 1.71 g. MNIR custodie, nr. prov. 47. 


\section{Imperiul Roman}

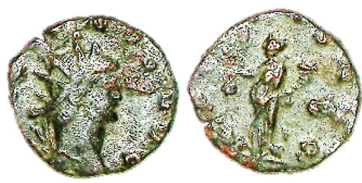

Gallienus

antoninianus

Avers: [...GALLIEN]VS [AVG], bust cu barbă, spre dr., cu coroană radiată.

Revers: [...] S AVG?, Genius ținând patera și cornucopiae; sau divinitate feminină, cu pungă sau căciulă în mâna dr. și cornucopiae în mâna st.; simbol sau literă(?) în câmp dr.

AE, ax: 6, greutate: 1.55 g. MNIR custodie, nr. prov. 49.

\section{Imperiul Roman}
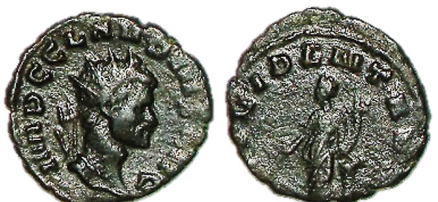

Marcus Aurelius Claudius (Claudius II Gothicus)

antoninianus

Avers: IMP C CLAVDIVS AVG, bustul împăratului, cu mustăți și barbă, purtând coroană radiată; cuirasat şi drapat; suliță (ș.a. ?) în spatele bustului.

Revers: [PRO]VIDENT AV[G], Providentia în picioare, cu capul spre st., ținând o vergea şi un sceptru lung, cu cotul st. sprijinit de o coloană. Batere excentrică, partea de jos a reversului (unde ar trebui să fie globul) nu este vizibilă, iar coloana scurtă, doar pe jumătate.

Tip RIC 5, 94, Roma, nedatat (268-270), dar cu acest tip de bust.

AE, ax: 7, greutate: 2.26 g. MNIR custodie, nr. prov. 50.

\section{Zona Hațegului, jud. Hunedoara, anterior anului 2013}

Din zona Hațegului, dintr-un loc neprecizat, provine un tezaur constituit din cel puțin 72 de denari romani imperiali. Piesele au toate aceeași patină mată și se găsesc într-o stare de conservare foarte bună. Tezaurul se încheie, probabil, undeva în a doua jumătate a secolului al II-lea (Antoninus Pius, Marcus Aurelius?). În curs de publicare (DM).

\section{Sânpetru de Câmpie/Sângeorgiu de Câmpie, com. Sânpetru de Câmpie, jud. Mureș, din punctul numit (La) Comoară, tezaur}

Un grup de 29 de denari romani imperiali² ar face, foarte probabil, parte din tezaurul împrăștiat cunoscut în zonă și intrat în literatura de specialitate sub numele de Sângeorgiu de Câmpie.

Despre compoziția tezaurului de la Sângeorgiu de Câmpie ${ }^{3}$ s-au păstrat informații sumare: 57 de denari imperiali, emişi între Augustus și Volusian, din care aproximativ jumătate provin de la împăraţi din dinastia Severilor. Grupul de denari romani imperiali amintit aici se încadrează cronologic ${ }^{4}$ în intervalul de timp cunoscut al emisiunilor reprezentate în tezaurul de la Sângeorgiu de Câmpie.

MNIR custodie.

\section{Tărtăria, jud. Alba, săpături arheologice sistematice, Podul Tărtaria Vest, campania 2016}

Denar roman imperial găsit în timpul campaniei de săpături arheologice din 2016 (17 iunie 2016), la Tărtaria, Podul Tărtaria Vest (S 032, caro D; adâncimea față de nivelul actual: 0.30 m; deasupra complexului), de către Vlad Rumega-Irinuş.

\footnotetext{
Moisil 2021, 122-137.

Depeyrot și Moisil, 2008, 174-175, nr. 84, cu bibliografia aferentă.

4 Moisil 2021, 124.
} 
1. Imperiul Roman

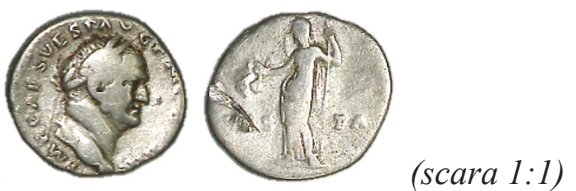

Vespasianus

denarius

Avers: IMP CAES VESP AVG P M COS IIII, cap laureat spre dr.

Revers: VES-TA, Vesta în picioare, jumătate spre st., cu simpulum în mâna dr. și sceptru lung în mâna st.

RIC $2^{2}$ 360; pl. 2, nr. 360; Roma, a. 72-73.

AR, ax: 8, $2.51 \mathrm{~g}$. Cu urme de uzură pe ambele fețe; pe revers, urme de lovire cu un obiect ascuțit (cu o cazma, la decapare).

(D. Moisil, V. Rumega-Irinuș)

\section{Turda, jud. Cluj, tip de descoperire neprecizat (probabil depozit/tezaur monetar)}

Trei monede de bronz de la Filip Arabul și Gordian III, având pe revers provinciile Dacia și Moesia, ar proveni din zona menționată (Al. Süto); fără alte detalii. Două au aceeași patină de culoare verde.

1. Imperiul Roman
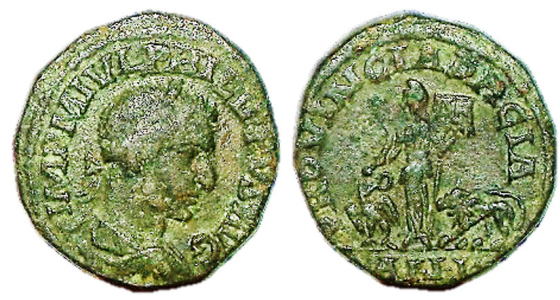

Dacia

Filip Arabul

sestertius

Avers: IMP M IVL PHILLIPVS AVG, bust laureat, drapat și cuirasat, spre dr.

Revers: PROVINCIA DACIA, AN.I. în exergă; pe stindard, D(acia) F(elix). Personificarea provinciei Dacia în picioare, cu un stindard inscripționat D F în st., cu phlax în dr., în poziție de atac; vultur și leu (însemnele legiunilor cantonate în Dacia, a V-a Macedonica și a XIII-a Gemina) la picioarele ei.

Pick 1, tip A, a. 246 (iulie) - 247 (iulie).

AE, ax: 1, greutate: $16.78 \mathrm{~g}$. MNIR custodie nr. prov. AS 59.

2. Imperiul Roman
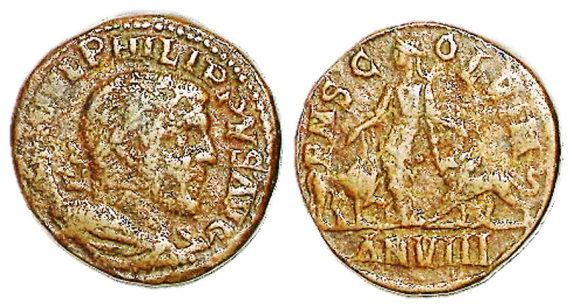

Filip Arabul

Viminacium

sestertius

Avers: IMP M IVL PHILLIPVS AVG, bust laureat, drapat și cuirasat, spre dr.

Revers: P M S C-OL VIM, AN VIII în exergă; personificarea provinciei Moesia în picioare, cu capul spre st., având mâinile aşezate deasupra unui taur (în st.) și a unui leu (în dr.) - însemnele legiunilor cantonate în această provincie. Pick 104, tip A, Viminacium..

AE, ax: 1, greutate: 18.35 g. MNIR custodie nr. prov. AS 69. 


\section{Imperiul Roman}
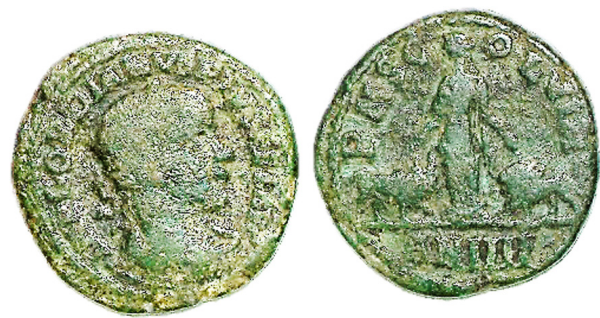

Gordianus III

Viminacium

sestertius(?)

Avers: IMP GORDIANVS PIVS [FEL] AVG, bust laureat, drapat și cuirasat, spre dr.

Revers: P M S C-OL VIM, AN IIII(?) în exergă; Provincia Moesia în picioare, cu capul spre st., având mâinile aşezate deasupra capetelor unui taur (st.) și a unui leu (dr.) - însemnele legiunilor cantonate în această provincie.

Pick 83, Viminacium.

AE, ax: 1, greutate: $17.02 \mathrm{~g}$. MNIR custodie nr. prov. AS 70.

\section{1. jud. Sălaj, România, depozit/tezaur monetar, după 1990}

Două tetradrahme de tip thasian, foarte friabile, rupte, cu urme ale trecerii prin foc, având ambele depuneri de sol de culoare bej pe suprafață, ar proveni din zona Sălajului (Al. Süto); fără detalii suplimentare. MNIR custodie.

\section{Tetradrahmă de tip Thasos}
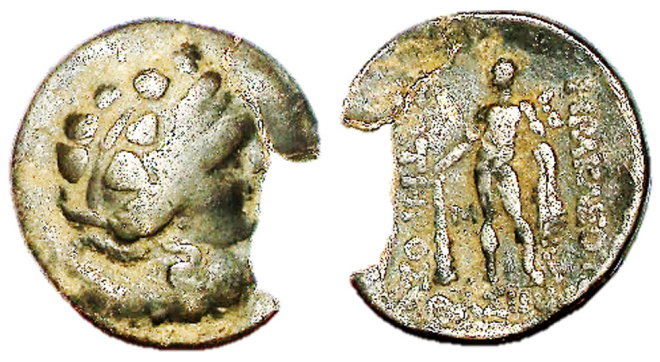

Avers: Capul lui Dyonisos, cu cunună de iederă, spre dr.

Revers: HPAK $\Lambda E O \_/ \Sigma O T H P O \Sigma / / \Theta A \Sigma I \Omega N$, Heracles nud, în picioare, cu capul spre st., ținând măciucă în mâna dr. Între măciucă și corp, M (sau M).

AR, ax: 11, greutate: 15.22 g. Ruptă, integritate 90\%. MNIR custodie nr. prov. 56.
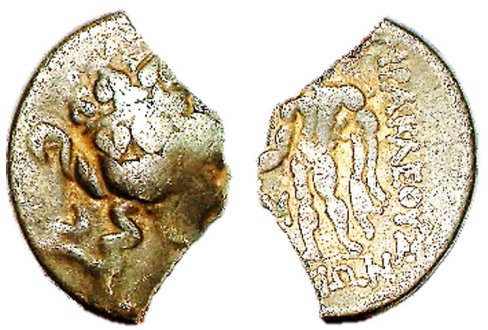

\section{Tetradrahmă de tip Thasos}

Avers: Capul lui Dyonisos, cu cunună de iederă, spre dr.

Revers: HPAK $\Lambda E O Y \Sigma /[\Sigma \mathrm{OTHPO} \Sigma] / /[\Theta \mathrm{A} \Sigma] \mathrm{I} \Omega \mathrm{N}$, Heracles nud, în picioare, cu capul spre st., ținând măciucă în mâna dr. Între măciucă și corp, monograma M.

AR, ax: 11, greutate: 10.44 g. Ruptă, integritate cca 35\%. MNIR custodie nr. prov. 57. 
12. Transilvania, România, ulterior anului 2010 (?)

Piesa ar fi fost achiziţionată din regiunea Transilvaniei, de pe teritoriul provinciei romane Dacia (A. Pânzaru). Nu avem detalii suplimentare asupra acestei descoperiri. MNIR custodie.

1. Imperiul Roman

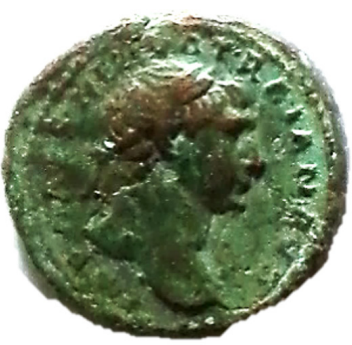

Traianus

Semis

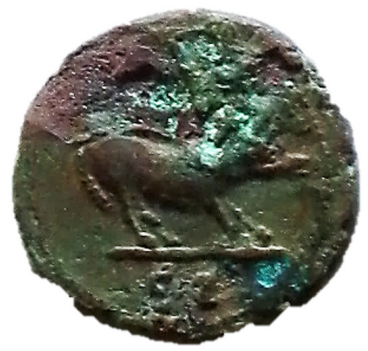

(scara 2:1)

Avers: IMP CAES NERVA TRAIAN AVG; bustul laureat al lui Traian, spre dr.

Revers: Lupoaica spre dr., SC în exergă.

MIR 599b, Roma, cca 109.

RIC 2692 (quadrans). Strack 485 (quadrans).

AE, ax: 7, 3.09 g. MNIR custodie nr. prov. AP/1/4.

\section{România, loc de descoperire neprecizat (de pe linia Dunării, din Banat sau Oltenia?) \\ (D. Moisil. M. Georgescu)}

Cinci monede romane târzii din bronz, respectiv din bronz argintat, găsite într-un loc neprecizat; tipul de descoperire din care provin nu este cunoscut. Includem rezultatele analizelor XRF efectuate la MNIR ${ }^{5}$ asupra pieselor, pentru a facilita studiul producției de monedă în atelierele romane târzii de la Antiochia, Cyzic, Constantinopol și Siscia.

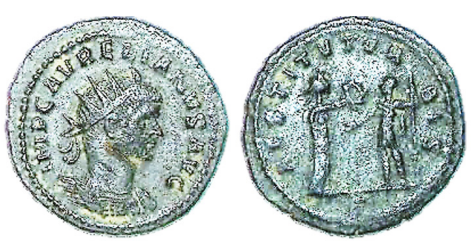

1. Imperiul Roman

Aurelianus

Antiochia

antoninianus

Avers: IMP C AVRELIANVS AVG, bust spre dr., cuirasat, cu coroană radiată.

Revers: RESTITVT OR-BIS, $\Gamma($ ?) în exergă. Un personaj feminin, în picioare, oferă o cunună împăratului, aflat în picioare, în fața ei, ținând în mâna st. sceptru.

RIC 5, 1, 386, Antiochia, per. III?

AE, ax: 6, 3.49 g. MNIR custodie nr. prov. 3.

\footnotetext{
Analizele au fost efectuate la Muzeul Naţional de Istorie a României, Secția de Investigații Fizico-Chimice și Biologice, cu un spectrometru cu fluorescenţă de raze X tip InnovX Systems Alpha Series (XRF) dotat cu anticatod din W, detector în dispersie de energie tip SiPIN cu răcire prin efect Peltier. Pentru identificarea compoziției chimice a monedelor, prin analiză de suprafață, tensiunea de lucru a fost de $35 \mathrm{kV}$, intensitatea 40 microA şi timpul de achiziţie de $120 \mathrm{~s}$.
} 
Tabel 1. Compoziția metalului determinată la suprafața monedei, prin fluorescență de raze X (XRF).

\begin{tabular}{lccccccccccc}
\hline \multirow{2}{*}{ Descriere } & \multicolumn{10}{c}{ Elemente chimice (\%) } \\
\cline { 2 - 13 } & $\mathrm{Cu}$ & $A g$ & $S n$ & $P b$ & $F e$ & $Z n$ & $A u$ & $B i$ & $N i$ & $T i$ \\
\hline avers & 91.14 & 3.77 & 2.3 & 2.08 & 0.56 & 0.14 & $\leq 0.001$ & $\leq 0.001$ & $\leq 0.001$ & $\leq 0.001$ \\
\hline revers & 90.37 & 4.03 & 2.52 & 2.81 & 0.12 & 0.14 & $\leq 0.001$ & $\leq 0.001$ & $\leq 0.001$ & $\leq 0.001$ \\
\hline
\end{tabular}

2. Imperiul Roman

Constantinus I

Constantinopolis

centenionalis

Avers: CONSTANTINVS MAX AVG, bust drapat, spre dr., cu o cunună cu rozete și gemă centrală.

Revers: GLOR-IA EXERC-ITVS, doi soldați ținând fiecare înspre exterior câte o lance, iar înspre interior, scut; între ei, două stindarde.

CONSA*

LRBC 1010, Constantinopolis, a. 330-335.

AE, ax: 5, 2.47 g. MNIR custodie nr. prov. 5.

Tabel 2. Compoziția metalului determinată la suprafața monedei, prin fluorescență de raze X (XRF)

\begin{tabular}{lccccccccccccc}
\hline \multirow{2}{*}{ Descriere } & \multicolumn{10}{c}{ Elemente chimice (\%) } \\
\cline { 2 - 7 } & $\mathrm{Cu}$ & $\mathrm{Sn}$ & $\mathrm{Ag}$ & $\mathrm{Fe}$ & $\mathrm{Zn}$ & $\mathrm{Au}$ & $\mathrm{Ni}$ & $\mathrm{Sb}$ & $\mathrm{Bi}$ & $\mathrm{As}$ & $\mathrm{Ti}$ \\
\hline avers & 89.7 & 5.43 & 2.68 & 1.09 & 0.62 & 0.11 & 0.08 & 0.16 & 0.14 & $\leq 0.001$ & $\leq 0.001$ & $\leq 0.001$ \\
\hline revers & 87.6 & 7.15 & 2.96 & 1.15 & 0.62 & 0.15 & 0.11 & 0.12 & 0.15 & $\leq 0.001$ & $\leq 0.001$ & $\leq 0.001$ \\
\hline
\end{tabular}

3. Imperiul Roman

Cyzicus

centenionalis

Avers: VRBS - ROMA, bustul Romei cu coif, spre st.

Revers: Lupoaica păşind spre st.; dedesubt, gemenii sugând; deasupra, două stele.

SMK

LRBC 1219, 1232, 1248 sau 1259, Cyzicus, a. 330-335.

AE, ax: 12, 2.32 g. MNIR custodie nr. prov. 4. 
Tabel 3. Compoziția metalului determinată la suprafața monedei, prin fluorescență de raze X (XRF).

\begin{tabular}{lcccccccccccc}
\hline \multirow{2}{*}{ Descriere } & \multicolumn{10}{c}{ Elemente chimice (\%) } \\
\cline { 2 - 6 } & $P b$ & $S n$ & $A g$ & $A u$ & $F e$ & $Z n$ & $N i$ & $T i$ & $B i$ & $A s$ \\
\hline avers & 86.66 & 9.22 & 2.46 & 1.07 & 0.24 & 0.2 & 0.1 & 0.05 & $\leq 0.001$ & $\leq 0.001$ & $\leq 0.001$ \\
\hline revers & 86.98 & 8.88 & 2.49 & 1.11 & 0.2 & 0.17 & 0.11 & 0.05 & $\leq 0.001$ & $\leq 0.001$ & $\leq 0.001$ \\
\hline
\end{tabular}

4. Imperiul Roman

Valentinianus I

Siscia

$A E 3$

Avers: DN VALENTINI-ANVS P F AVG, bust drapat, spre dr., cu diademă perlată dublă şi gemă centrală.

Revers: SECVRITAS - REIPVBLICAE, Victoria înaripată păşind spre st., cu o cunună în mâna dr. și ramură de palmier în st., peste umăr.

A

DASISC

LRBC 1296, Siscia, a. 364-367.

AE, ax: 8, 2.11 g. MNIR custodie nr. prov. 6 .

Tabel 4. Compoziția metalului determinată la suprafața monedei, prin fluorescență de raze X (XRF).

\begin{tabular}{lccccccccccc}
\hline \multirow{2}{*}{ Descriere } & \multicolumn{10}{c}{ Elemente chimice (\%) } \\
\cline { 2 - 12 } & $C u$ & $P b$ & $S n$ & $F e$ & $Z n$ & $N i$ & $A u$ & $A g$ & $B i$ & $T i$ \\
\hline avers & 97.4 & 1.98 & 0.28 & 0.22 & & 0.12 & $\leq 0.001$ & $\leq 0.001$ & $\leq 0.001$ & $\leq 0.001$ \\
\hline revers & 96.37 & 2.95 & 0.24 & 0.24 & 0.1 & 0.11 & $\leq 0.001$ & $\leq 0.001$ & $\leq 0.001$ & $\leq 0.001$ \\
\hline
\end{tabular}

5. Imperiul Roman

Theodosius I

Cyzicus

AE4

Avers: DN THEODO-SIVS PF AVG, bust drapat, spre dr., purtând diademă cu gemă centrală.

Revers: SALVS REI - PVBLICAE, Victoria înaripată păşind spre st., cu trofeu pe umărul st.; în câmp dr. jos, un prizonier aşezat; în câmp st., +P în ligatură.

SMKA

LRBC 2569 și 2577, Cyzicus, off. A?, a. 383-392 și 393-395.

AE, ax: 12, 0.93 g. MNIR custodie nr. prov. 7. 
Tabel 5. Compoziția metalului determinată la suprafața monedei, prin fluorescență de raze X (XRF ).

\begin{tabular}{lccccccccccc}
\hline \multirow{2}{*}{ Descriere } & \multicolumn{10}{c}{ Elemente chimice (\%) } \\
\cline { 2 - 13 } & $\mathrm{Cu}$ & $\mathrm{Pb}$ & $\mathrm{Sn}$ & $\mathrm{Fe}$ & $\mathrm{Zn}$ & $\mathrm{Bi}$ & $\mathrm{V}$ & $\mathrm{Ni}$ & $\mathrm{Au}$ & $\mathrm{Ag}$ & $\mathrm{Ti}$ \\
\hline avers & 93.52 & 3.52 & 1.7 & 0.47 & 0.31 & 0.27 & 0.16 & 0.05 & $\leq 0.001$ & $\leq 0.001$ & $\leq 0.001$ \\
\hline revers & 91.9 & 4.64 & 1.87 & 0.83 & 0.29 & 0.25 & 0.19 & 0.03 & $\leq 0.001$ & $\leq 0.001$ & $\leq 0.001$ \\
\hline
\end{tabular}

\section{România, loc de descoperire neprecizat}

Piese antice variate, provenind de pe teritoriul României, fără nici un fel de alte detalii. Colecția domnului A. Pânzaru; MNIR custodie.

\section{Macedonia}

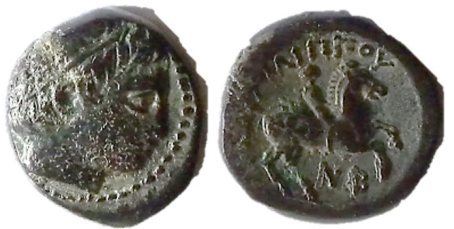

Filip II (359-336 î. Hr.)

Avers: Bustul laureat al lui Apollo spre dr.

Revers: Călăreț spre dr.; legenda ФI $\Lambda$ IППOY deasupra; monograma AV (în ligatură) și B, sub burta calului.

SNG Copenhaga 592.

AE, ax: 4/5, 6.55 g. MNIR custodie nr. prov. AP/1/1.
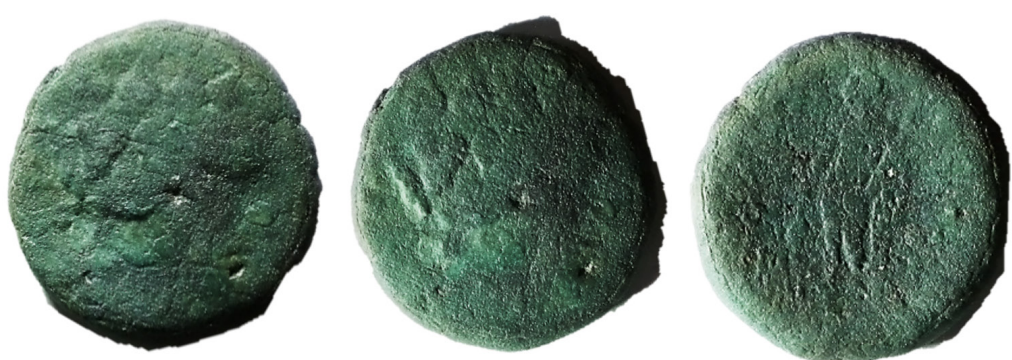

2. Imitație(?) după o emisiune grecească autonomă (tetradrahmă tip Thasos?)

Avers: Capul lui Dionysos sau al lui Apollo, cu frunze de iedera?, spre dr.

Revers: Hercules? în picioare, cu capul spre st., cu blana leului din Nemeea şi ciomag în mâna dr. AE (aparent fără argint), ax: 11, 10.85 g. MNIR custodie nr. prov. AP/1/2. 


\section{Imperiul Roman}

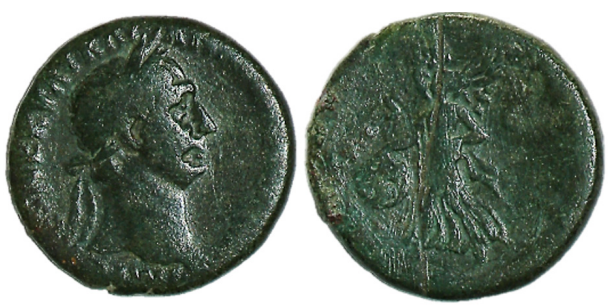

Traianus

as

Avers: IMP CAES NERVA TRAIAN [AVG GERM PM], bust laureat, spre dr.

Revers: [TR POT COS II PP], S-C în camp, Victoria păşind spre st., ținând ramură de palmier şi clipeus virtutis cu inscripția SPQR.

MIR 33a, Roma, a. 98, februarie - toamnă.

RIC 2 395; Strack 315.

AE, ax: 7, 10.67 g. MNIR custodie nr. prov. AP/1/3.

\section{Imperiul Roman}

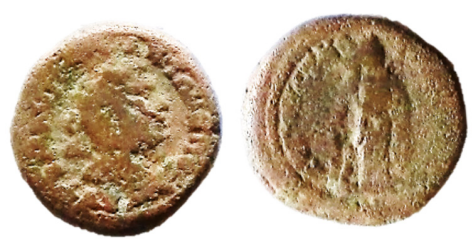

Caracalla, Elagabal?

Emisiune colonială (Balcani)?

$\mathrm{AE}$

Avers: AVT...[ANTONEINO?], bust laureat, spre dr.

AE, ax: 1, 4.59 g. MNIR custodie nr. prov. AP/1/5.

\section{Imperiul Roman}

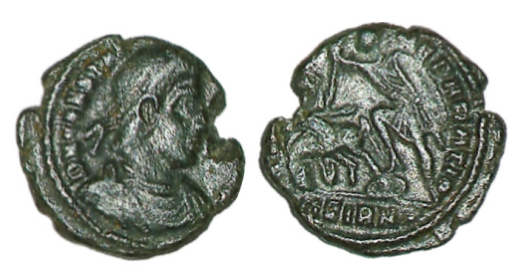

Constantius II

\section{AE3}

Avers: DN CONSTAN[...], bust spre dr., drapat, cuirasat, cu diademă perlată şi gemă centrală. Legenda de avers este ștanțată parțial în afara flanului (a doua ei parte).

Revers: [FEL TEMP]-REPARATIO, împărat cu piciorul pe scut, purtând scut oval pe brațul st., străpunge cu sulița un călăreț căzând de pe calul îngenuncheat; călărețul întinde mâna st. spre împărat, cerând îndurare.

[?]ASIRM*

LRBC 1605, Sirmium, a. 351-354.

AE, ax: 12, 2.66 g. Cu urme de decupaj (rotunjit) al flanului din tiparul de turnare. MNIR custodie nr. prov. AP/1/6. 
6. Imperiul Roman

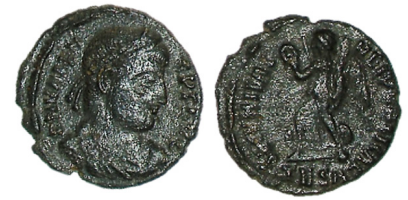

Valens

Thessalonica

AE3

Avers: DN VALEN-S PF AVG, bust spre dr., drapat, cuirasat, cu diademă perlată.

Revers: SECVRITAS REIPVBLICAE, Victoria cu cunună în dr. și ramură de palmier în st., pășind spre st. $[\cdot]$ TESA

LRBC 1710? Thessalonica, a. 364-367.

AE, ax: 5, 2.06 g. Flan neregulat, din care lipsesc mici fragmente; mic decupaj la baza bustului imperial. MNIR custodie nr. prov. AP/1/7.

7. Imperiul Bizantin

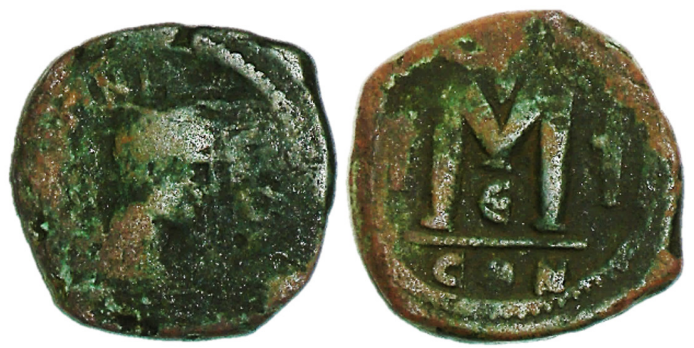

Iustinianus

40 nummia

Avers: [DN IV]STINIA-NVS[PPAVC], bust dr. din profil.

Revers:

$+$

$+\mathrm{M}+$

$\epsilon$

CON

Tip MIBE 87 (dar legenda de av. despărțită ...NIA-NVS, nu ...NI-A...), Constantinopolis, officina 5; a. 527, 1 august.

AE, ax: 8, 15.73 g. Cu urme puternice de oxid de culoare verde pe suprafață. MNIR custodie nr. prov. AP/1/8.

DELIA MOISIL

Muzeul Național de Istorie a României, București.

delia.moisil2@gmail.com 


\section{ABREVIERI}

Ceka

LRBC

MIBE

MIR

Moushmov

Pick

RIC $1^{2}$

RIC 2

RIC $2^{2}$

RIC 3

RIC 4

RIC 5

RIC 6

RIC 7

RIC 8

RIC 10

SNG Copenhaga

SNG Stancomb

Strack
Ceka, H., 1972. Questions de numismatique illyrienne avec un catalogue des monnaies d'Apollonie et Durrhachium. Tirana.

Carson, R., Hill, P. și Kent, J., 1976. Late Roman Bronze Coinage, Londra.

Hahn, W. și Metlich, M. A., 2000. Money of the Incipient Byzantine Empire. Viena: Veröffentlichungen des Instituts für Numismatik und Geldgeschichte der Universität Wien.

Woytek, B., 2010. Die Reichsprägung des Kaisers Traianus (Moneta Imperii Romani, 14). Viena.

Moushmov, N. A., 1912. Ancient Coins of the Balkan Peninsula and the Coins of the Bulgarian Monarchs (în bulg.). Sofia : G. I. Gavazov. (wildwinds.com/ coins/moushmov/index.html, accesat in 07-08.2021).

Pick, B., 1899. Die Antiken Münzen Nord-Griechelands, vol. 1: Dacien und Moesien. Berlin.

Sutherland, C. H. V., 1984. The Roman Imperial Coinage, vol. 1: From 31 BC to $A D$ 69, Londra.

Mattingly, H. și Sydenham, E. A., 1968. The Roman Imperial Coinage, vol. 2: Vespasian to Hadrian, Londra.

Carradice, I. A. și Buttrey, T. V., 2007. The Roman Imperial Coinage, vol. 2, 1, ediția a 2-a revizuită: From AD 69-96 Vespasian to Hadrian. Londra.

Mattingly, H. și Sydenham, E. A., 1930. The Roman Imperial Coinage, vol. 3: Antoninus Pius to Commodus. Londra.

Mattingly, H. și Sydenham, E. A., 1936. The Roman Imperial Coinage, vol. 4, 1: Pertinax to Geta. Londra.

Mattingly, H. și Sydenham, E. A., 1938. The Roman Imperial Coinage, vol. 4, 2: Macrinus to Pupienus. Londra.

Mattingly, H. și Sydenham, E. A., 1949. The Roman Imperial Coinage, vol. 4, 3: Gordian III - Uranius Antoninus, Londra.

Webb, P. H., 1962. The Roman Imperial Coinage, vol. 5, 1: Valerian to Florian, Londra.

Webb, P. H., 1962. The Roman Imperial Coinage, vol. 5, 2: Probus to Amandus, Londra.

Sutherland, C. H. V., 1973. The Roman Imperial Coinage, vol. 6: From Diocletian's reform (A.D. 294) to the death of Maximinus (A.D. 313), Londra.

Bruun, P., 1966. The Roman Imperial Coinage, vol. 7: Constantine and Licinius, A.D. 313 - 337, Londra.

Kent, J. P. C., 1981. The Roman Imperial Coinage, vol. 8: The family of Constantine I, A.D. 337-364, Londra.

Kent, J. P. C., 1994. The Roman Coinage, vol. 10, Spink and Son Ltd., Londra.

Sylloge Nummorum Graecorum, The Royal Collection of Coins and Medals Danish National Museum, vol. 2: Thrace and Macedonia. New Jersey: Sunrise Publications Inc. 1982.

Sylloge Nummorum Graecorum, vol. 11: The William Stancomb Collection of Coins of the Black Sea Region, The British Academy, Oxford University Press \& Spink and Son Limited, 2000.

Strack, P. L., 1931. Untersuchungen zur römischen Reichsprägung des zweiten Jahrhunderts, vol. 1: Die Reichsprägung zur Zeit des Traian. Stuttgart. 


\section{BIBLIOGRAFIE}

Böhm, L. 1861. Geshichte des Temeser Banats, II. Leipzig: Verlag von Otto Wigand.

Depeyrot, G. și Moisil, D. 2008a. Les tresors de deniers de Trajan à Balbin en Roumanie. Wetteren: Moneta.

Depeyrot, G. și Moisil, D., 2008b. Les trésors de deniers et d'antoniniens de Gordien III à Aurélien en Roumanie. Wetteren: Moneta.

Moisil, D. 2021. O restituire numismatică: monede din tezaurul de la Sângeorgiu de Câmpie, com. Sânpetru de Câmpie, jud. Mureș, din punctul numit La Comoară, în: Tezaure monetare antice: 122-137. București, în curs de apariție. 